\title{
Transfer and Properties of Some Natural and Suicide Replicons in Pasteurella multocida
}

\author{
By NDUBISI A. NNALUE*† AND B. A. D. STOCKER \\ Department of Microbiology and Immunology, Stanford University, Stanford, \\ California 94305, USA
}

(Received 14 April 1989; revised 12 July 1989; accepted 4 September 1989)

\begin{abstract}
We tested the transfer of several plasmids and transposons from Escherichia coli to Pasteurella multocida by filter mating. Two plasmids, pRKTV5 (pRK2013::Tn7) and pUW964 (pRKTV5 ::Tn5), were derived from pRK2013 - a narrow-host-range plasmid with the broadhost-range IncP conjugation genes. Most $P$. multocida transconjugants obtained with pRKTV5 had Tn7 insertions in the chromosome but some had insertions of the whole plasmid. By contrast, all the transconjugants obtained with pUW964 had insertions of this plasmid or a deleted variant. pUW964 mediated low-frequency transfer of $\mathrm{Tn} 7$ or chromosomal markers between $P$. multocida strains. Broad-host-range IncP plasmid RP4 (RK2) did not yield selectable transconjugants in $P$. multocida but two plasmids derived by $\mathrm{Tn} 5$ insertion into a kanamycinsensitive derivative of RP4 did yield transconjugants. pSUP1011, a narrow-host-range p15A replicon with the RP4 mob region allowing mobilization by the IncP conjugation genes also yielded transconjugants while several other plasmids tested did not transfer markers to $P$. multocida.
\end{abstract}

\section{INTRODUCTION}

Pasteurella multocida is an agent of disease in livestock of economic importance such as cattle (Thomson et al., 1969), poultry (Rhoades \& Rimler, 1984) and pigs (Rutter \& Mackenzie, 1984). The vaccines in current use are not very effective. More effective vaccines are needed but genetic methods for strain construction have yet to be developed for Pasteurella. Such methods would enable derivation of mutants and facilitate analyses of the several identified virulence factors (Il'ina \& Zasukhin, 1975; Glorioso et al., 1982; Lugtenberg et al., 1984; Rutter \& Mackenzie, 1984; Pedersen \& Elling, 1984; Snipes \& Hirsh, 1986; Truscott \& Hirsh, 1988) of this species.

Temperate phages (Gadberry \& Miller, 1977, 1978) and plasmids have been described in $P$. multocida and in a related species $P$. haemolytica, but have not been used for genetic studies. Small, non-conjugative plasmids $\left(<10 \times 10^{6} \mathrm{Da}\right)$ which determine sulphonamide and streptomycin resistance have been reported (Silver et al., 1979; Berman \& Hirsh, 1978; Zimmerman \& Hirsh, 1979) and a large P. multocida plasmid of $28.5 \times 10^{6} \mathrm{Da}$ was shown to be transmissible to Escherichia coli but only in association with a co-resident $7.2 \times 10^{6}$ Da plasmid (Hirsh et al., 1981). To our knowledge there have been no reports of introduction of exogenous plasmids or transposons into $P$. multocida. Useful vectors for investigation of Pasteurella genetics therefore remain to be constructed or discovered.

We have investigated the transfer and properties in $P$. multocida of plasmid replicons and transposons that have been useful for genetic studies of other bacteria. We tested naturally-

\footnotetext{
$\dagger$ Present address: Karolinska Institute, Department of Clinical Bacteriology, F:72, Huddinge University Hospital, S-14186, Huddinge, Sweden.
}

Abbreviations: FCS, foetal calf serum. 
occurring plasmids and three kinds of suicide vectors: chimeric plasmids whose replication origins were derived from replicons with a narrow host-range for maintenance but whose conjugation genes were derived from promiscuous replicons (Weiss \& Falkow, 1983; Weiss et al., 1983; Sato et al., 1981; Simon et al., 1983); a Tn5 containing, replieation-defective IncX plasmid able to replicate in the presence of phage $\Lambda$-pir (Kolter et al., 1978; Miller \& Mekalanos, 1988), and a derepressed derivative of the IncI $\alpha$ plasmid ColIb loaded with $\operatorname{Tn} 5$ or Tn 10 (Boulnois et al., 1985). These replicons were chosen because they have been shown to have a wide host range for conjugation.

\section{METHODS}

Bacterial strains and their cultivation. P. multocida strains RG12, RG31, RG32 and P2100 were obtained from Dr Ron Griffith of Iowa State University, Ames, Iowa, USA. RG12, isolated as ISVDL29532A, is of bovine origin and was chosen for use as recipient because, unlike most isolates, it was sensitive to all the antibiotics tested. RG31 and RG32 are streptomycin- and nalidixate-resistant mutants respectively, obtained from RG12 after mutagenesis with EMS and selection for resistance on gradient plates. The rifampicin-resistant mutants, PM108 and PM109, were isolated from RG31 and P2100, respectively, by the same procedure. E. coli strains HB101 and C600 are described by Maniatis et al. (1982); others are described in other references (Table 1). Pasteurella strains were grown in L-broth supplemented to $10 \%$ with foetal calf serum (FCS) or on L-agar plates with $0.25 \mathrm{ml}$ of FCS spread on the surface (LA-FCS). E. coli strains were grown in L-broth or L-agar. Antibiotics were used at the following concentrations: kanamycin, $25 \mu \mathrm{g} \mathrm{ml}^{-1}$; spectinomycin, $60 \mu \mathrm{g} \mathrm{ml}^{-1}$; trimethoprim, $20 \mu \mathrm{g} \mathrm{ml}^{-1}$; nalidixic acid, $20 \mu \mathrm{g} \mathrm{ml}^{-1}$; rifampicin, $5 \mu \mathrm{g} \mathrm{ml}^{-1}$; ampicillin, 5 or $10 \mu \mathrm{g} \mathrm{ml}^{-1}$; tetracycline, 5 or $10 \mu \mathrm{g} \mathrm{ml}^{-1}$ and chloramphenicol, $10 \mu \mathrm{g} \mathrm{ml}^{-1}$.

Plasmids. The plasmids used in this study are listed in Table 1. Plasmid pRK2013 contains the conjugation and kanamycin-resistance genes of RK2 but the replication origin of ColE1 (Figurski \& Helinski, 1979). pRKTV5 is pRK2013 with its kanamycin-resistance gene (non-transposon borne) inactivated by insertion of transposon $\mathrm{Tn} 7$ (Weiss et al., 1983). Tn7 determines resistance to spectinomycin, streptomycin and trimethoprim. pUW964 was derived from pRKTV 5 by $\mathrm{Tn} 5$ insertion (Weiss et al, 1983). pSUP1011 consists of the p15A replication origin, the ori $\mathrm{T}$ of RP4 (identical to RK2) and Tn5. It is mobilized by an integrated derivative of RP4 in donor strain SM10. The above plasmids thus have replication origins of narrow-host-range replicons (ColE1 or p15A) but the conjugation genes of a broad-host-range plasmid (RP4). pJM703.1 : : Tn5tet, has an R6K replication origin and the mob (mobilization) region of RK2 but lacks a functional pir gene whose product is required for the initiation of plasmid replication (Kolter et al., 1978). It is mobilized in the same way as pSUP1011 and is maintained only in strains that complement its pir defect, such as $E$. coli strains infected with the $\Lambda$-pir phage. We derived plasmids pNA100 and pNA101 by inserting Tn 5 as described by Ruvkun \& Ausubel (1981) into pRK212.1, a kanamycinsensitive derivative of RK2 (Figurski \& Helinski, 1979). Plasmids pLG221 and pLG223 are ColIb-drd replicons containing $\operatorname{Tn} 5$ and $\operatorname{Tn} 10$, respectively, which have been used as suicide vehicles (Boulnois $e t$ al., 1985).

Table 1. Plasmids

\begin{tabular}{|c|c|c|c|}
\hline Plasmid (host) & Genetic description* & $\begin{array}{c}\text { Incompatibility type, } \\
\text { phenotype } \dagger\end{array}$ & Source or reference \\
\hline pRK2013 (HB101) & $\begin{array}{l}\text { Transfer genes of RP4 } \\
\text { cloned in ColE1 }\end{array}$ & ColEl $\mathrm{Tra}^{+}$ & Figurski \& Helinski (1979) \\
\hline 101) & pRK2013 kan::Tn7 & ColE1 $\mathrm{Tra}^{+} \mathrm{Sp} \mathrm{Tp}$ & Weiss et al. \\
\hline 101) & pRK2013 kan::Tn7 xyz::Tn5 & ColE1 $\mathrm{Tra}^{+} \mathrm{Sp} \mathrm{Tp} \mathrm{Km}$ & Weiss \\
\hline SUP1011 & $\begin{array}{l}\text { oriT of RP4 cloned in } \\
\text { DACYC184::Tn } 5\end{array}$ & $\mathrm{Tra}^{-} \mathrm{Mob}^{+} \mathrm{Km} \mathrm{Cm}$ & Simon et al. (1983) \\
\hline $\begin{array}{l}\text { pJM703.1::Tn5tet } \\
\text { (SM10^pir) }\end{array}$ & oriT of RP4 cloned in R6Kpir & 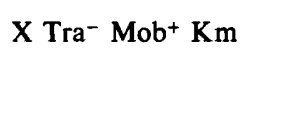 & $\begin{array}{l}\text { Ralph Isberg, Tufts } \\
\text { Univerity School of } \\
\text { Medicine, Boston, USA; } \\
\text { Miller \& Mekalanos (1988) }\end{array}$ \\
\hline JA100 (HB101) & In & $\mathrm{P} \mathrm{Tra}^{+}$Ap Km Tc & This work \\
\hline JA101 (HB101) & pRK212.1::Tn5.6 & P Tra ${ }^{+}$Ap Km Tc & Thi \\
\hline $\mathbf{K} 212.1$ & $k_{a n} \mathrm{~S}$ R4 & P Tra ${ }^{+}$Ap Tc & Figurski \& Helinski (1979) \\
\hline 4 (J5) & $\mathbf{R P}$ & $\mathrm{P} \mathrm{Tra}^{+}$Ap Km Tc & Datta et al. (1971) \\
\hline 88 (MV12) & R38 & W Tra + Tp Su & Gill et al. (1978) \\
\hline$(10)$ & $d r d-1:: \operatorname{Tn} s$ & $\mathrm{I} \alpha \mathrm{Tra}^{+} \mathrm{Km}$ & Boulnois et al. (1985) \\
\hline G223 (Bwa7) & ColIb drd-1::Tn 10 & $\mathrm{I} \alpha \mathrm{Tra}^{+} \mathrm{Tc}$ & Boulnois et al., (1985) \\
\hline
\end{tabular}

* kan, kanamycin resistance.

$\dagger \mathrm{Ap}$, ampicillin resistance; $\mathrm{Cm}$, chloramphenicol resistance; $\mathrm{Km}$, kanamycin resistance; $\mathrm{Sp}$, spectinomycin resistance; Tc, tetracycline resistance; $\mathrm{Tp}$, trimethoprim resistance. 
Filter-mating. Overnight cultures of donor $(0.5 \mathrm{ml})$ and recipient $(1 \mathrm{ml})$ in L-broth were mixed and impinged on a membrane filter. The filter was incubated overnight on an LA-FCS plate, transferred to $5 \mathrm{ml}$ L-broth in a tube and vortexed for $1 \mathrm{~min}$. The resulting suspension was plated on selective media containing the appropriate antibiotic and either nalidixic acid or rifampicin to select against donor cells. Every mating experiment included a control in which donor and recipient were each impinged on separate filters and then treated exactly as the mating pair. The results of such controls were used to determine the frequencies of spontaneous mutants in donor and recipient populations.

Stability of plasmid markers in transconjugants. A clone was picked from agar, tested for retention of plasmid resistance markers and then passaged through broth over $10 \mathrm{~d}$ by daily transfer of $0.1 \mathrm{ml}$ of old culture to $10 \mathrm{ml}$ of fresh broth. The tenth broth culture was plated and 54 colonies were tested for plasmid markers. Each such clone is estimated to be a product of at least 66 generations of growth in the absence of selection.

Molecular analyses. Strains were examined for plasmid content by two methods for small-scale plasmid isolation (Birnboim \& Doly, 1979; Portnoy et al., 1981). Plasmids for use as probes were purified by $\mathrm{CsCl}_{2}$ density-gradient centrifugation and labelled with $\left[\alpha^{-32} \mathrm{P}\right] \mathrm{dCTP}$ by nick translation to $>10^{7}$ c.p.m. $\mu \mathrm{g}^{-1}$. Probes were used to detect plasmid-specific sequences either directly on colonies (Grunstein \& Hogness, 1975) or on EcoRI-digested chromosomal DNA by Southern hybridization (Maniatis et al., 1982).

\section{RESULTS}

\section{Exchange of plasmids $p R K T V 5, p U W 964$ or their markers}

Spectinomycin resistance was transferred from $E$. coli HB101(pRKTV5) to P. multocida RG32 at a mean frequency of $10^{-3}$ per recipient (Table 2). Tansconjugants ( 120 in total, 20 from each of six matings) were tested and found also to be resistant to trimethoprim, indicating that they had acquired Tn7. Plasmid DNA was not found in any of 12 selected transconjugants (two per mating) when examined by two methods (Birnboim \& Doly 1979; Portnoy et al., 1981) which we have used to isolate plasmids from other $P$. multocida strains (data not shown). When probed with ${ }^{32} \mathrm{P}$-labelled plasmids by the colony hybridization method (Grunstein \& Hogness, 1975), all 12 clones hybridized to pRKTV5 but only two hybridized to pRK2013 (data not shown). Thus 10 clones had Tn7 insertions while two apparently maintained pRKTV5. A somewhat different result was obtained with pUW964. Each of the resistance markers of this plasmid, kanamycin (Tn5) or spectinomycin/trimethoprim (Tn7) were transferred from E. coli HB101(pUW964) to P. multocida RG32 at the same frequency, $10^{-5}$ per recipient (Table 2). All of 27 transconjugants selected from nine separate matings (three clones selected per cross, one for each resistance marker) had all the resistance markers of pUW964, which indicated that the plasmid was maintained in every transconjugant. These transconjugants also did not contain free plasmid DNA, consistent with the expectation that ColE1 replicons would not be maintained in $P$. multocida. However they all hybridized to ${ }^{32} \mathrm{P}$-labelled pRK2013, showing that each contained at least a non-transposon segment of pUW964 and thus did not derive from simultaneous transpositions of $\operatorname{Tn} 5$ and $\operatorname{Tn} 7$ (data not shown).

Table 2. Transfer of plasmids to P. multocida by conjugation

$$
\begin{aligned}
& \text { E. coli donor } \quad P \text { multocida } \\
& \text { recipient }
\end{aligned}
$$

\section{P. multocida recipient}

HB101(pRKTV5)

HB101(pUW964)

SM10(pSUP1011)

SM10(pSUP1011)

HB101(pNA100)

HB101(pNA101)

MV12(R388)

J5(RP4)

C600(pLG221)

Bwa7(pLG223)
RG32

RG32

PM108

PM109

PM108

PM109

PM108

PM109

RG32

RG32

RG32

RG32

\section{Selection}

$\mathrm{Sp}$

Sp Km or Tp

$\mathrm{Km}$

$\mathrm{Km}$

$\mathrm{Km}$

$\mathrm{Km}$

$\mathrm{Km}$

Km

Tp

$\mathrm{Km}$

$\mathrm{Km}$

Tc
Transfer frequency* (no. of tests)

$$
\begin{aligned}
& 10^{-3}(6) \\
& 10^{-5}(5) \\
& 10^{-3}(3) \\
& 4 \times 10^{-4}(3) \\
& 5 \times 10^{-5}(2) \\
& 5 \times 10^{-4}(2) \\
& 10^{-6}(2) \\
& 5 \times 10^{-7}(2) \\
& <10^{-9}(2) \\
& 10^{-9}(4) \\
& 7 \times 10^{-8}(3) \\
& <10^{-9}(3)
\end{aligned}
$$

* Mean number of transfers per recipient cell. 


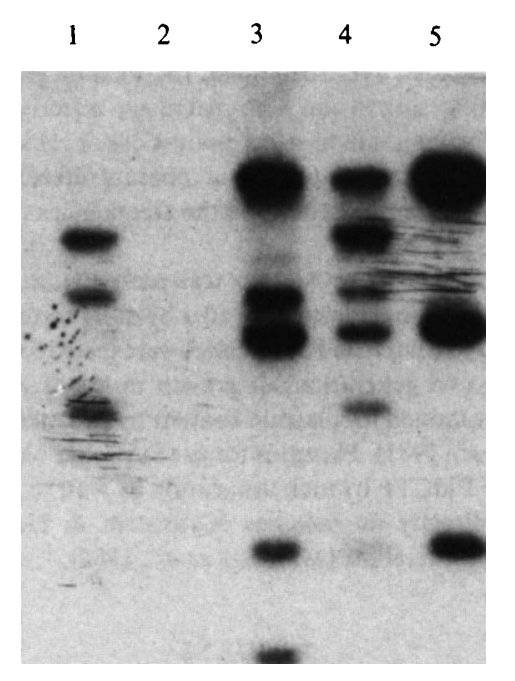

Fig. 1. Analysis of chromosomal DNA from RG32 and three transconjugants by digestion with EcoRI and probing with ${ }^{32}$ P-labelled plasmid pUW964. Lanes 1 to 5 contain DNA from PM102, RG32, PM103, PM104 and $\mathrm{CsCl}_{2}$-banded pUW964, respectively.

The maintenance mechanism of pUW964 was subsequently investigated by tests of markerinstability and probing of EcoRI-digested chromosomal DNA from three transconjugants, PM100, PM103 and PM104. Trimethoprim and spectinomycin resistance, both determined by $\mathrm{Tn} 7$, were stable in all three strains. Fifty four clones from each strain tested after passage through broth retained both markers. Kanamycin resistance, determined by $\mathrm{Tn} 5$, was likewise stable in PM104 but was unstable in PM100 and PM103 so that only two and 31 respectively of the 54 clones from each strain tested after broth-passage retained this marker. That only kanamycin resistance was unstable and that kanamycin-sensitive segregants did not act as genetic donors (see below), suggested that pUW964 was present in these strains as a Tn7promoted cointegrate. By cointegrate we mean an integrated plasmid with one copy of the same transposon at either end irrespective of integration mechanism. The results (Fig. 1) of probing EcoRI-digested chromosomal DNA with ${ }^{32} \mathrm{P}$-labelled pUW964 support this view. The DNA from PM103 (lane 3) and PM100 (not shown) had more bands that hybridized to pUW964 than expected if the plasmid was present in these strains as an independent replicon. This was also the case with PM104 (lane 4) even though kanamycin resistance was stable in this strain. Another strain examined, PM102 (lane 1), had only three bands as did pUW964 (lane 5) isolated from HB101, but none of these bands were of the same size in the two samples. Moreover the sizes of the three bands in PM102 were the same as those of the three novel bands in PM104. Together with the fact that PM102 was the only transconjugant unable to act as a genetic donor (see below), the above data suggest that pUW964 is also integrated in the chromosome in this strain but had sustained a deletion that removed at least some conjugation genes.

\section{Donor activity by pRKTV5 and pUW964 in P. multocida}

Three $P$. multocida transconjugants which carry pUW964 (PM100, PM103 and PM104) transferred spectinomycin or kanamycin resistance to $E$. coli $\mathrm{HB} 101$ at frequencies between $10^{-3}$ and $2 \times 10^{-5}$ per recipient cell. PM102, though resistant to spectinomycin, trimethoprim and kanamycin, did not transfer markers to $E$. coli $\left(<10^{-9}\right.$ per recipient cell for each). Two kanamycin-sensitive segregants, one each derived from PM100 and PM103, also did not transfer spectinomycin resistance to $E$. coli $\left(<10^{-9}\right.$ per recipient cell for each marker). E. coli 
Table 3. Genetic exchange between P. multocida strains

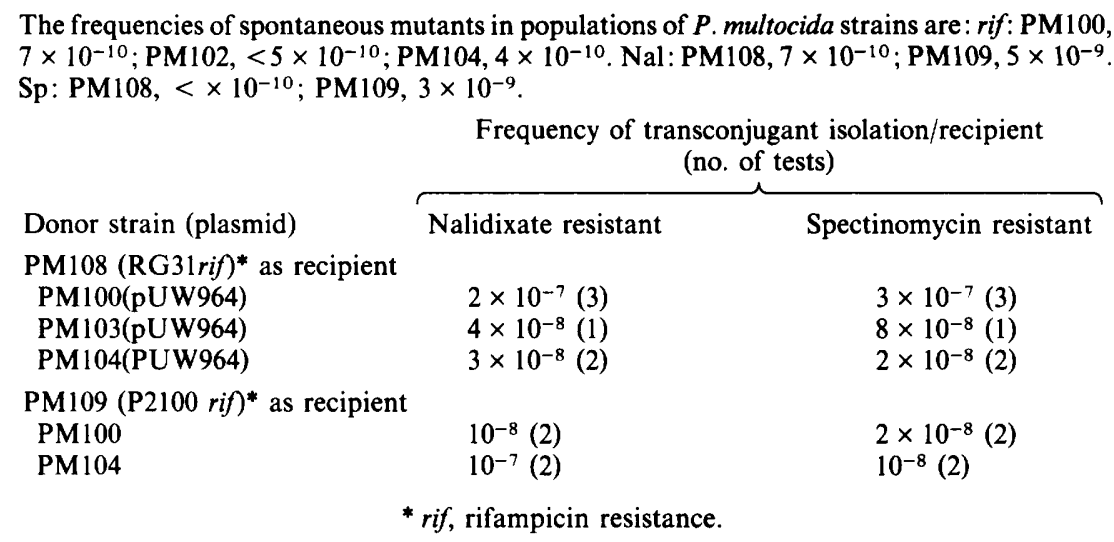

transconjugants obtained after mating with Pasteurella donors did not always acquire unselected markers. While the markers of $\operatorname{Tn} 7$ were always inherited by such transconjugants, that of $\operatorname{Tn} 5$ was absent at a frequency of $4 \times 10^{-2}$ to $11 \times 10^{-2}$ among spectinomycin- or trimethoprimresistant transconjugants. This suggests deletion events removing all or part of $\operatorname{Tn} 5$ when pUW964 was resident in $P$. multocida, which agrees with the previously observed instability of this marker. Plasmids extracted from two spectinomycin-resistant but kanamycin-sensitive $E$. coli transconjugants were smaller in size than pUW964 whereas those obtained from 10 transconjugants that had both markers were of the same size as pUW964. pRKTV5 also had donor activity in P. multocida and was transferred from PM107 and PM114 to HB101 at frequencies of $10^{-3}$ to $4 \times 10^{-4}$ per recipient cell.

Transfer of markers between $P$. multocida strains were tested with the pUW964-carrying strains PM100, PM103 and PM104 as donors and the rifampicin-resistant (rif) recipients, PM108 (RG31rif) or PM109 (P2100rif). Transfer of spectinomycin (Table 3) but not of kanamycin resistance was observed. The spectinomycin-resistant transconjugants were also resistant to trimethoprim and sensitive to nalidixic acid, consistent with aquisition of $\operatorname{Tn} 7$ by recipient cells. The apparent transfer only of $\operatorname{Tn} 7$ to Pasteurella recipients and the rather low transfer frequencies compared to those obtained with $E$. coli as recipient suggested that the Pasteurella transconjugants resulted from primary chromosome mobilization and subsequent $\operatorname{Tn} 7$ transposition. We therefore tested the mobilization of markers by co-selecting for nalidixic acid resistance, a marker on the chromosomes of donor strains, and rifampicin resistance, a chromosomal marker of the recipient strains. Transfer of nalidixate resistance occurred at $10^{-7}$ to $10^{-8}$ per recipient cell (Table 3 ) which, compared to control experiments, represents about 40 to 300 times the frequencies of spontaneous nalidixate-resistant mutants in the recipient population or of rifampicin-resistant mutants in the donor population. The transconjugants did not inherit any of the markers of pUW964. Non-availability of mutants prevented a more rigorous test of mobilization by selection for co-transfer of chromosomal markers. The above transfers, however, were consistent between experiments and occurred at frequencies seen in some mobilization systems (Smith et al., 1986; Dreyfus \& Iglewski, 1985; Weiss \& Falkow, 1983). The data thus can be most plausibly explained on the basis of chromosome mobilization.

\section{Transfer of other plasmids to $P$. multocida}

Kanamycin-resistant $P$. multocida transconjugants were isolated by mating with $E$. coli hosts of pSUP1011, pNA100 and pNA101 (Table 2). The transconjugants in each case retained all non-transposon-borne plasmid markers showing that they retained the whole plasmids. Plasmids RP4, R388, pLG221, pLG223 and pJM703. $1:$ : Tn5tet, did not transfer markers to $P$. multocida (Table 2) at frequencies significantly different from controls. 


\section{DISCUSSION}

Plasmids of the $\mathrm{P}$ and $\mathrm{W}$ incompatibility groups are well known for their ability to transfer to many bacterial genera and have been used to mediate genetic exchange in various bacteria (Dreyfus \& Iglewski, 1985; Tatra \& Goodwin, 1983; Weiss \& Falkow, 1983; Tucker \& Pemberton, 1979). Our results show that the conjugation genes of a $P$ plasmid (RK2) can transfer pRKTV5 and pUW964 to $P$. multocida. As expected of ColE1 replicons (Falkow, 1975) these plasmids did not replicate independently in $P$. multocida. About $80 \%$ of the transconjugants isolated with pRKTV5 carried Tn7 insertions, while the rest and all transconjugants isolated with pUW964 retained the plasmids. pUW964 behaves differently in Bordetella pertussis, where it has been used to isolate Tn5 insertions (Weiss \& Falkow, 1983). Experimental evidence suggests that, in at least some of the transconjugants, the plasmids were present as Tn7-generated cointegrates (Southern blots and loss of kanamycin resistance only). Although $\mathrm{Tn} 7$ lacks a resolvase and is not known to transpose by a cointegrate pathway, there are other possible pathways by which an apparent-cointegrate can be formed: (i) by simple insertion of a $\operatorname{Tn} 7-\mathrm{xyz}-\mathrm{Tn} 7$ segment from a dimeric plasmid molecule as demonstrated for Tn 5 by Berg (1983), or (ii) by a simple insertion of $\operatorname{Tn} 7$ as a first step, followed by a single crossover between the integrated copy and the $\operatorname{Tn} 7$ in a second plasmid molecule in the same cell.

Plasmids pRKTV5 and pUW964 had a donor activity in P. multocida and were efficiently transferred back to $E$. coli, as intact or deleted plasmids. Attempts to transfer pUW964 between $P$. multocida strains resulted only in transfer of $\operatorname{Tn} 7$ and a chromosomal marker. The transfer of pUW964 from $P$. multocida to $E$. coli but not to other $P$. multocida strains may be a consequence of the difference in the maintenance mechanisms of this plasmid in the two species. If pUW964 is excised at low frequency from the integrated state it may be transmitted to $E$. coli, but hardly to other $P$. multocida strains where maintenance is by integration. Transfer only of $\mathrm{Tn} 7$ between $P$. multocida strains can be explained by chromosome mobilization. In an Hfr transfer beginning at oriT one of the two copies of $\mathrm{Tn} 7$ in a cointegrate will be transmitted early and is available for transposition. As part of the plasmid is transmitted only as a terminal segment, a recipient such as $E$. coli (which can maintain pUW964 as a free replicon) should only infrequently inherit an intact plasmid by this mechanism; a $P$. multocida recipient should never inherit an intact plasmid. The behaviour of pUW964 in P. multocida is in several ways similar to that of RP4 in Myxococcus xanthus (Breton et al., 1985). It was observed that RP4 transmitted to $M$. xanthus from $E$. coli integrated into the chromosome and was transferable, intact or as an R-prime, back to $E$. coli. It did not transfer between $M$. xanthus strains but mediated transfer of chromosomal Tn5 insertions. We did not observe transfer of Tn5 present in pUW964 between $P$. multocida, perhaps because of late entry or of inability to transpose in $P$. multocida. The latter seems plausible because none of the several other Tn5-carrying replicons tested (pJM703.1: :Tn5tet, pSUP1011, pLG221, pNA100 and pNA101) evoked Tn5 insertions even though some of them were transferred to $P$. multocida at moderate (pNA100 and pNA101) or high (pSUP1011) frequency.

The two naturally-occurring broad-host-range plasmids, R388 (IncW) and RP4 (IncP) did not transfer their respective trimethoprim-and kanamycin-resistance markers to $P$. multocida. It was therefore surprising that plasmids pNA100 and pNA101 derived by Tn 5 insertion into a kanamycin-sensitive derivative of RP4 were transferred and maintained in $P$. multocida. Perhaps the kanamycin-resistance gene of RP4 is not expressed in P. multocida. On the other hand it is possible that $\operatorname{Tn} 5$ had contributed to maintenance, for example by promoting integration.

$P$. multocida presents an unknown genetic system in which the replicons we have tested behaved abnormally. We established a low-frequency system for chromosome transfer between $P$. multocida strains. As pRKTV5 behaves as a suicide vehicle in $P$. multocida $80 \%$ of the time it could be exploited for transposon mutagenesis. However its parent replicon, pRK2013, if loaded with a transposon unable to promote integration, should make a better vehicle for this purpose. 


\section{REFERENCES}

BERG, D. E. (1983). Structural requirements for IS50mediated gene transposition. Proceedings of the National Academy of Sciences of the United States of America 80, 792-796.

Berman, S. M. \& Hirsh, D. C. (1978). Partial characterization of $\mathrm{R}$ plasmids from Pasteurella multocida isolated from turkeys. Antimicrobial Agents and Chemotherapy 14, 348-352.

Birnbolm, H. C. \& Doly, J. (1979). A rapid alkaline extraction procedure for screening recombinant plasmid DNA. Nucleic Acids Research 7, 1513-1523.

Boulnois, G. J., Varley, J. M., Sharpe, G. S. \& Franklin, F. C. H. (1985). Transposon donor plasmids, based onColIb-P9 for use in Pseudomonas putida and a variety of other gram negative bacteria. Molecular and General Genetics 200, 65-67.

Breton, A. M., Jaoua, S. \& Guespin-Michel, J. (1985). Transfer of plasmid RP4 to Myxococcus xanthus and evidence for its integration into the chromosome. Journal of Bacteriology 161, 523528.

Datta, N., Hedges, R. W., Shaw, E. J., Sykes, R. B. \& RICHMOND, M. H. (1971). Properties of an R factor from Pseudomonas aeruginosa. Journal of Bacteriology 108, 1244-1249.

DREYFus, L. A. \& IGlewSKI, B. H. (1985). Conjugation mediated genetic exchange in Legionella pneumophila. Journal of Bacteriology 161, 2629-2632.

Falkow, S. (1975). Infectious Multiple Drug Resistance. London: Pion.

FiguRSKI, D. H. \& Helinski, D. R. (1979). Replication of an origin containing derivative of plasmid RK2 dependent on a plasmid function provided in trans. Proceedings of the National Academy of Sciences of the United States of America 76, 1648-1652.

GadberRy, J. L. \& Miller, N. G. (1978). Characterization of a Pasteurella multocida bacteriophage. American Journal of Veterinary Research 39, 1565 1566.

GadberRy, J. L. \& Miller, N. G. (1977). Use of bacteriophages as an adjunct in the identification of Pasteurella multocida. American Journal of Veterinary Research 38, 129-130.

Gill, R., Hefrron, F., Dougan, G. \& Falkow, S. (1978). Analysis of sequences transposed by complementation of two classes of transposition-deficient mutants of Tn3. Journal of Bacteriology 136, 747-756.

Glorioso, J. C., Jones, G. W., Rush, H. G., Pentler, L. J., Darif, C. A. \& Coward, J. E. (1982). Adhesion of type A Pasteurella multocida to rabbit pharyngeal cells and its possible role in rabbit respiratory tract infections. Infection and Immunity 35, 1103-1109.

Grunstein, M. \& Hogness, D. S. (1975). Colony hybridization: a method for the isolation of cloned DNAs that contain a specific gene. Proceedings of the National Academy of Sciences of the United States of America 72, 3961-3965.

Hirsh, D. C., MaRTin, L. D. \& Rhoades, K. R. (1981). Conjugal transfer of an R-plasmid in Pasteurella multocida. Antimicrobial Agents and Chemotherapy 20, 415-417.

IL'INA, Z. M. \& ZASUKhIN, M. I. (1975). Role of
Pasteurella toxins in the pathogenesis of infectious atrophic rhinitis. Sbornik nauchnykh rabot sibirskogo zonalnogo nauchno-issledovatel'skogo veterinarnogo instituta 25, 76-86.

Kolter, R., InUzuKa, M. \& Helinski, D. R. (1978). Trans-complementation-dependent replication of a low-molecular weight origin fragment from plasmid R6K. Cell 15, 1199-1208.

LUGTENBerg, B., VAN BOXTEL, R. \& De JoNG, M. (1984). Atrophic rhinitis in swine; correlation of Pasteurella multocida pathogenicity with membrane proteins and lipopolysaccharide patterns. Infection and Immunity 46, 48-54.

Maniatis, T., Fritsch, E. F. \& Sambrook, J. (1982). Molecular Cloning: a Laboratory Manual. Cold Spring Harbor, NY: Cold Spring Harbor Laboratory.

Miller, V. L. \& Mekalanos, J. J. (1988). A novel suicide vector and its use in construction of insertion mutations: osmoregulation of outer membrane proteins and virulence determinants in Vibrio cholerae requires toxR. Journal of Bacteriology 170, 25752583.

Pedersen, K. B. \& Elling, F. (1984). The pathogenicity of atrophic rhinitis in pigs induced by toxigenic Pasteurella multocida. Journal of Comparative Pathology 94, 203-214.

Portnoy, D. A., Moseley, S. L. \& Falkow, S. (1981). Characterization of plasmids and plasmid-associated determinants of Yersinia enterocolitica pathogenesis. Infection and Immunity 31, 775-782.

RhoAdes, K. R. \& Rimler, R. B. (1984). Avian pasteurellosis. In Diseases of Poultry, 8th edn., pp. 141-156. Edited by M. S. Hofstad, H. J. Barnes, B. W. Calnek, W. M. Reid \& H. W. Yoder. Ames: Iowa State University Press.

Rutter, J. M. \& MaCkenzie, A. (1984). Pathogenesis of atrophic rhinitis in pigs: a new perspective. Veterinary Record 114, 393-396.

Ruvkun, G. B. \& Ausubel, F. M. (1981). A general method for site-directed mutagenesis in prokaryotes. Nature, London 289, 85-88.

Sato, M., Staskawicz, B. J., Panapolous, N. J., Peters, S. \& Honma, M. (1981). A host-dependent hybrid plasmid suitable as a suicidal carrier of transposable elements. Plasmid 6, 325-331.

Smith, C. G., Coote, J. G. \& Parton, R. (1986). Rplasmid mediated chromosome mobilization in Bordetella pertussis. Journal of General Microbiology 132, 2685-2692.

SNIPES, K. P. \& HiRsh, D. C. (1986). Association of complement sensitivity with virulence of Pasteurella multocida isolated from turkeys. Avian Diseases 30, 500-504.

Silver, R. P., Leming, B., Garon, C. F. \& HJerpe, C. A. (1979). R-plasmids in Pasteurella multocida. Plasmid 2, 493-497.

Simon, R., Priefer, U. \& Puhler, A. (1983). A broad host range mobilization system for in vivo genetic engineering: transposon mutagenesis in gram negative bacteria. Biotechnology 1, 784-789.

TATRA, P. K. \& Goodwin, P. M. (1983). R-plasmid mediated chromosome mobilization in the faculta- 
tive methylotroph Pseudomonas AM1. Journal of General Microbiology 129, 2629-2632.

Thompson, R. G., Benson, M. L. \& Savan, M. V. (1969). Pneumonic pasteurellosis of cattle: microbiology and immunology. Canadian Journal of Comparative Medicine 33, 194-206.

TruscotT, W. M. \& Hirsh, D. C. (1988). Demonstration of an outer membrane protein with antiphagocytic activity in Pasteurella multocida of avian origin. Infection and Immunity 56, 1538-1544.

Tucker, W. T. \& Pemberton, J. M. (1979). Conjugation and chromosome transfer in Rhodopseudomonas sphaeroides mediated by $\mathbf{W}$ and $\mathbf{P}$ group plasmids. FEMS Microbiology Letters 5, 173-176.
Weiss, A. A. \& Falkow, S. (1983). Transposon insertion and subsequent donor formation promoted by Tn501 in Bordetella pertussis. Journal of Bacteriology 153, 304-309.

Weiss, A. A., Hewlett, E. L., Myers, G. A. \& FALKow, S. (1983). Tn5 induced mutations affecting virulence factors of Bordetella pertussis. Infection and Immunity 42, 33-41.

Zimmerman, M. L. \& Hirsh, D. C. (1979). Demonstration of an $\mathrm{R}$ plasmid in a strain of Pasteurella haemolytica isolated from feedlot cattle. American Journal of Veterinary Research 41, 166-169. 